\title{
COMPOSIÇÃO BOTÂNICA E QUALIDADE DE PASTAGEM DE AZEVÉM ASSOCIADA COM FABÁCEAS DE INVERNO SOB PASTEJO CONTÍNUO, NA REGIÃO SUL DO PARANÁ'
}

\author{
BOTANICAL COMPOSITION AND QUALITY OF RYEGRASS PASTURE \\ ASSOCIETED WITH WINTER LEGUMES UNDER CONTINUOUS GRAZING \\ CONDITION, IN THE SOUTHERN REGION OF PARANÁ ${ }^{1}$
}

\author{
Oswaldo Teruyo IDO² \\ Anibal de MORAES ${ }^{3}$ \\ Amir PISSAIA ${ }^{4}$ \\ Adelino PELISSARI ${ }^{4}$ \\ Henrique Soares KOEHLER ${ }^{5}$
}

\begin{abstract}
RESUMO
Uma pastagem de azevém (Lolium multiflorum Lam.) associada com três fabáceas de inverno: trevo vermelho (Trifolium pratense L.), trevo branco (Trifolium reppens L.) e cornichão (Lotus corniculatus L.), submetida a quatro ofertas de forragem (OF), $4 ; 8 ; 12$ e $16 \mathrm{~kg}$ de massa seca (MS) $100 \mathrm{~kg}$ de peso vivo (PV), foi avaliada num delineamento em blocos ao acaso, com duas repetições, no período de julho a novembro de 1995, no Centro de Estações Experimentais do Setor de Ciências Agrárias - Canguirí - UFPR, em PinhaisPR com objetivo de avaliar o efeito de ofertas de forragem sobre a composição botânica e qualidade da pastagem. O método de pastejo foi o contínuo com lotação variável, utilizando-se a técnica "put-and-take". A composição botânica da pastagem foi modificada pela ação das diferentes OF. Com a diminuição na oferta de forragem ocorreu aumento na percentagem ple plantas daninhas na pastagem. A qualidade da forragem e a relação folha:colmo foram reduzidas com o aumento do acúmulo de MS ha ${ }^{-}$. Com o avanço no estádio de desenvolvimento do azevém, ocorreu decréscimo gradativo no teor de proteína bruta (PB), entretanto, com o aumento da participação relativa das fabáceas, principalmente do trevo vermelho a partir de outubro, ocorreu aumento gradativo no teor de PB da pastagem.
\end{abstract}

Palavras-chave: associação azevém-leguminosas, relação folha:colmo; composição botânica; teor de proteína; massa seca.

\begin{abstract}
A ryegrass pasture (Lolium multiflorum Lam.) associated with winter legumes: red clover (Trifolium pratense L.), white clover (Trifolium repens $L$.) and birdsfoot trefoil (Lotus corniculatus L.), submitted to four levels of herbage allowance (HA), namelly $4 ; 8 ; 12$ e 16 $\mathrm{kg}$ of dry matter (DM) $100 \mathrm{~kg}$ of the liveweight (LW), was evaluated in a randomized complete block design with two replications. The trial was carried out in July until November 1995, at the Canguiri, Center of Experiment Station SCA- UFPR, at Pinhais, PR with the objective of determinate the effect of levels of herbage allowance above botanical composition and pasture quality. The "put-and-take" technique in a continuous grazing system with variable stocking rate was used. Pasture botanical composition was modified by differents HA. Reducing $\mathrm{HA}$ qaused increase in the percentage of weed component in pasture. Forage quality and leaf-stem ratio were reduced when DM accumulation ha increased. A gradual decrease of crude protein (CP) content occurred as the stage of development of ryegrass advanced, however, increasing the legumes participation, mainly white clover, since October, occurred a gradual increase in pasture CP.
\end{abstract}

Key-words: Ryegrass and legumes association; leaf:stem ratio; protein content; dry matter.

\footnotetext{
${ }^{1}$ Parte da dissertação apresentada pelo primeiro autor à UFPR para obtenção do título de M.SC.

${ }^{2} \mathrm{Eng}^{\circ} \mathrm{Agr}^{\circ}$, D.Sc., Prof. Adjunto do Depto. de Fitotecnia e Fitossanitarismo do Setor de Ciências Agrárias da Universidade Federal do Paraná, caixa postal 19061, CEP 81531-990, Curitiba, PR. - e-mail: ido@ufpr.br.

${ }^{3} \mathrm{Eng}^{\circ} \mathrm{Agr}^{\circ}$, D.Sc., Prof. Adjunto, Orientador, Depto. de Fitotecnia e Fitossanitarismo do SCA/UFPR

${ }^{4} E_{n g}{ }^{\circ}$ Agro ${ }^{\circ}$ D.Sc., Prof. Adjunto, Co-Orientador, Depto. de Fitotecnia e Fitossanitarismo do SCA/UFPR

${ }^{5}$ Eng ${ }^{\circ}$ Florestal, D.Sc., Prof. Adjunto, Co-Orientador, Depto. de Fitotecnia e Fitossanitarismo do SCA/UFPR.
} 


\section{INTRODUÇÃO}

Dentre as alternativas para a solução da oferta de forragem nas estações frias do ano na Região Sul do Brasil, o uso da associação de poáceas e fabáceas produtivas seria de grande valor, principalmente, pela manutenção de níveis adequados do ganho de peso, em virtude da presença da fabácea como melhoradora da qualidade da dieta colhida pelo animal e melhor distribuição estacional da qualidade da forragem produzida (18).

A composição botânica de uma pastagem pode ser drasticamente modificada como conseqüência do manejo de pastejo. Assim, espécies que podem se tornar dominantes em uma comunidade, sob condições de pastejo leve ou diferido, onde considerável crescimento é permitido, podem ser reduzidas ou eliminadas sob pastejo pesado e lotação contínua. Em condições de pastejo leve, comumente as espécies cespitosas de porte alto tendem a dominar as de porte baixo e estoloníferas, acontecendo o contrário em condições de pastejo pesado (2). Nas consorciações, é importante determinar a proporção entre as espécies, procurando conhecer a dinâmica da população da pastagem. É considerado como ideal a manutenção de 20 a 39\% de fabáceas na composição, para que se atinja boas produções $(1 ; 3 ; 4 ; 18 ; 19)$.

Quadros e Maraschin (18) em Guaíba-RS, estudaram o desempenho animal em misturas de espécies forrageiras de estação fria sob pastejo com lotação contínua, mantendo uma oferta de forragem (OF) de $6 \%$ do peso vivo (PV). Quantificaram valores de digestibilidade in vitro de matéria orgânica e percentagem de proteína bruta (PB) ao longo do período experimental entre 73 a $58 \%$ e 15 a $12 \%$, respectivamente, para as associações de azevém trevo branco - cornichão. Trabalhos à campo, em pastejo com lotação contínua, demonstram o efeito de diferentes níveis de ofertas de forragem na qualidade da pastagem nativa do Rio Grande do Sul. Escosteguy (5), Moojen (11), na mesma área experimental, observaram o mesmo comportamento em campo nativo quando submetido a diferentes ofertas $(4 ; 8 ; 12$; e $16 \%$ do PV), ou seja, na medida em que aumentava a oferta ocorria redução na percentagem de PB da forragem disponível.

Tanto no Paraná como em Santa Catarina, são poucas as informações de pesquisa envolvendo produção animal com espécies de inverno, apesar da reconhecida importância deste grupo de forrageiras, na composição de sistemas de produção de carne e leite (14).

O objetivo deste trabalho foi determinar 0 efeito de quatro ofertas de forragem sobre a composição botânica e a qualidade da pastagem de azevém, associada à três fabáceas de inverno, na Região Sul do Paraná, com o intuito de testar a hipótese: se a associação de azevém com fabáceas de inverno aumenta o teor de proteína bruta das pastagens então haverá aumento da qualidade, com melhoria do ganho de peso animal.

\section{METODOLOGIA}

O experimento foi conduzido sobre solo Latossolo Vermelho - Amarelo Álico, no Centro de Estações Experimentais do Setor de Ciências Agrárias - Canguiri - UFPR, município de Pinhais - PR, Região Metropolitana de Curitiba, entre as coordenadas $25^{\circ} 25^{\prime}$ de latitude sul e $49^{\circ} 08^{\prime}$ de longitude oeste e altitude entre as cotas 915 a 930 metros. O clima segundo a classificação de Koeppen é temperado do tipo Cfb (6).

A análise do solo da camada de 0 a $10 \mathrm{~cm}$ indicou como valores médios: $\mathrm{pH}(\mathrm{CaCl})=5,2 ; \mathrm{Al}^{+3}$ $=0,02 \mathrm{cmol}^{(+)} \mathrm{dm}^{-3} ; \mathrm{Ca}^{2+}=7,6 \mathrm{cmol}^{(+)} \mathrm{dm}^{-3} ; \mathrm{Mg}^{2+}=$ $4,7 \mathrm{cmol}^{(+)} \mathrm{dm}^{-3} ; \mathrm{P}=6,8 \mathrm{mg} \mathrm{dm}^{-3} ; \mathrm{K}=0,14 \mathrm{cmol}^{(+)} \mathrm{dm}^{-3}$; $\mathrm{C}=39 \mathrm{~g} \mathrm{dm}^{-3} ; \mathrm{V} \%=60$.

O semeadura direta das forrageiras de inverno, com 15 linhas espaçadas de $17 \mathrm{~cm}$, foi realizada no período de 18 a 20 de abril de 1995, com as seguintes quantidades de sementes por hectare: $25 \mathrm{~kg}$ de azevém comum (Lolium multiflorum Lam.); 2 $\mathrm{kg}$ de trevo branco (Trifolium repens L.); $5 \mathrm{~kg}$ de trevo vermelho (Trifolium pratense L.) e $5 \mathrm{~kg}$ de cornichão (Lotus corniculatus L.). As sementes das fabáceas foram previamente inoculadas com Rhizobium específicos, peletizadas e misturadas com as do azevém. O controle das plantas daninhas e a dessecação da pastagem de milheto (Pennisetum americanum (L.) Leeke), em mistura com infestação natural de capim papuã (Brachiaria plantaginea (Link.) Hitch) foram feitas através da aplicação de 2 litros ha $^{-1}$ do herbicida comercial glyphosate, nos dias $04 \mathrm{e}$ 05 de abril de 1995.

A calagem foi realizada à lanço, 12 dias de antecedência à semedura, utilizando $2 \mathrm{t} \mathrm{ha}^{-1}$ (Piquetes 01; 02; 03 e 04) e $5 \mathrm{t} \mathrm{ha}^{-1}$ (Piquetes 05; 06; 07 e 08) de calcário dolomítico. A adubação de manutenção foi realizada à lanço na semeadura, com $60 \mathrm{~kg}$ de $\mathrm{P}_{2} \mathrm{O}_{5}$ e $90 \mathrm{~kg}$ de $\mathrm{K}_{2} \mathrm{O}$ por ha. Aplicou-se em cobertura, 50 $\mathrm{kg}$ de $\mathrm{N} \mathrm{ha}^{-1}$ (uréia), parcelada em duas aplicações: $25 \mathrm{~kg} \mathrm{ha}^{-1}$ de $\mathrm{N}$ aos 27 dias e 2,5 $\mathrm{kg} \mathrm{ha}^{-1}$ aos 72 dias após a semeadura.

Os tratamentos aplicados foram, quatro ofertas de forragem definidos como $\mathrm{kg}$ de massa seca (MS) $100 \mathrm{~kg}^{-1}$ de peso vivo (PV) por dia. Os níveis foram de 4, 8, 12 e 16\% do PV, dispostos em delineamento em blocos ao acaso com duas repetições por tratamento, totalizando 8 parcelas (piquetes), com áreas variando de 1,1 a 1,5 ha. As subdivisões foram feitas por meio de um sistema de cercas eletrificadas, mantendo-se um corredor interno para facilitar a movimentação dos animais às áreas adjacentes e balança, para manter os animais reguladores. O método de pastejo foi o contínuo, com lotação variável, utilizando a técnica dos animais reguladores "put-and-take" (16). Utilizou-se dois animais "testers" (vacas em lactação da raça holandesa) previamente marcadas por tratamento, com peso médio de $499 \mathrm{~kg} / \mathrm{animal}$. Foi usado número variável de animais reguladores (vacas secas e/ou 
novilhas holandesas) com peso médio de 492 $\mathrm{kg} / \mathrm{animal}$, que eram manejadas de forma à manter os níveis desejados de oferta de forragem. O ajuste da carga animal (reguladores) foi realizado a cada 14 dias. Da semeadura ao início da utilização da pastagem transcorreram 89 dias. O período de utilização sob pastejo contínuo foi de 112 dias (17/07 a $06 / 11 / 95$ )

A estimativa do resíduo de MS da composição botânica e da freqüência das espécies da pastagem, foi feita por duas metodologias: a) uma apresentada por Tothill et al. (22) denominada Botanal, acrescida das melhorias sugeridas por Jones e Hargreaves (7) e b) a do Método do Disco, empregada por permitir ajuste mais expedito. As avaliações foram feitas antes do início do pastejo e posteriormente, a cada 28 dias (período experimental). A oferta de forragem real, ou seja, a oferta imposta, foi calculada da seguinte forma: 1) adição do resíduo médio de $M S$ ha ${ }^{-1}$ com a taxa de acúmulo estimada no período; 2) quociente deste valor pelo número de dias do período o que resultou no resíduo médio de MS ha ${ }^{-1} \mathrm{dia}^{-1}$; 3) o resultado, pelo quociente da carga animal e 4) finalmente, o valor da oferta real foi obtido pelo produto do resultado obtido em 3, por 100, para obtenção da percentagem da oferta. A cada 28 dias, iniciando na semana do pastejo, eram coletadas ao acaso vinte amostras por piquete, com a finalidade de separação dos componentes folha e colmo. As amostras, numa área correspondente ao disco de $0,10 \mathrm{~m}^{2}$, eram colhidas em pontos aleatórios dentro dos piquetes, formando no final uma amostra composta. Com o material ainda verde, separava-se o azevém das demais espécies. A seguir separava-se as folhas dos colmos. Estes componentes eram colocados em estufa a $65^{\circ} \mathrm{C}$ até peso constante, para determinação da MS. A relação folha:colmo foi calculada através do quociente, entre MS das folhas e MS dos colmos. Para análise da qualidade da pastagem eram feitas a cada 28 dias, amostragens de 20 pontos ao acaso por piquete. As coletas eram feitas cortando-se rente ao solo uma área correpondente ao disco de $0,10 \mathrm{~m}^{2}$ As amostras eram misturadas e uma sub - amostra de aproximadamente $500 \mathrm{~g}$ por piquete era pesada e levada em estufa para secagem até atingir peso constante e novamente, pesada, moída e peneirada com peneira de malha $1 \mathrm{~mm}$. Todo material moído era acondicionado em saco plástico, para determinação da qualidade: proteína bruta; fibra em detergente neutro e fibra em detergente ácido, através da técnica de análise NIRS -Near Infrared Reflectance Spectroscopy.

Todos os animais eram pesados no momento da entrada e da saída do experimento e a cada 28 dias. As pesagens foram realizadas após a ordenha da manhã. Para auxiliar no reajuste da carga animal foram necessárias pesagens intermediárias (cada 14 dias).

A relação da variável independente OF com as variáveis dependentes:resíduo de $\mathrm{MS} \mathrm{ha}^{-1}, \mathrm{~PB}$, fibra em detergente ácido, fibra em detergente neutro, relação folha:colmo e presença de plantas daninhas, foi estabelecida pela análise de regressão. Procurouse dentre os modelos o que melhor ajustava a relação entre as variáveis, testando-se as regressões linear e quadrática. Cada modelo foi submetido a análise de variância para determinar o nível de significância entre as variáveis. As análises foram feitas utilizando-se o manual simplificado de uso do programa MSTAT-C, elaborado por Koehler (9).

\section{RESULTADOS E DISCUSSÃO}

O período de avaliação da pastagem foi de julho a novembro de 1995, totalizando 112 dias, com carga animal média utilizada de $2.581 ; 1.643 ; 1.312$ e $1.005 \mathrm{~kg}$ de PV ha-1 $\mathrm{dia}^{-1}$, respectivamente para as ofertas de forragem de $4 ; 8 ; 12$ e $16 \%$. A partir do conhecimento da taxa de acúmulo de MS associado ao resíduo da pastagem, foi possível calcular as ofertas de forragem que definiram a OF real empregada (Tabela 1).

TABELA 1 - Resíduos médios e oferta de forragem avaliados na pastagem de azevém associada com fabáceas de inverno, pelos métodos do Disco e do Botanal no período de 17/07/95 a 06/11/95. CEEx-Canguiri, UFPR-SCA, Pinhais - PR.

\begin{tabular}{|c|c|c|c|c|c|}
\hline \multirow{2}{*}{$\begin{array}{c}\text { OFERTA } \\
\text { PRETENDIDA } \\
\% \text { PV }\end{array}$} & \multirow{2}{*}{$\begin{array}{c}\text { PIQUETE } \\
n^{\circ}\end{array}$} & \multicolumn{2}{|c|}{$\begin{array}{l}\text { RESÍDUO MÉDIO } \\
\left(\mathrm{kg} \mathrm{MS} \mathrm{ha}^{-1}\right)\end{array}$} & \multicolumn{2}{|c|}{$\begin{array}{c}\text { OFERTA DE FORRAGEM REAL } \\
(\% \text { PV })\end{array}$} \\
\hline & & Disco & Botanal & Disco & Botanal \\
\hline 4,0 & 02 & 1892 & 1322 & 4,4 & 3,5 \\
\hline 4,0 & 05 & 2073 & 1436 & 4,7 & 3,8 \\
\hline 8,0 & 04 & 2737 & 2665 & 8,7 & 8,6 \\
\hline 8,0 & 07 & 2949 & 2776 & 9,6 & 9,2 \\
\hline 12,0 & 03 & 3246 & 3550 & 12,9 & 13,8 \\
\hline 12,0 & 06 & 3321 & 3564 & 13,3 & 14,0 \\
\hline 16,0 & 01 & 3916 & 4107 & 18,6 & 19,2 \\
\hline 16,0 & 08 & 3925 & 4110 & 18,7 & 19,4 \\
\hline
\end{tabular}


Nos tratamentos de superpastejo (piquetes 02 e 05), com menor oferta de forragem, onde mantevese o nível residual de 1322 e $1436 \mathrm{Kg}$ de $\mathrm{MS}$ ha $^{-1}$ respectivamente, (Tabela 2 ), o azevém não conseguiu manter cobertura efetiva da área, diminuindo sua competição e permitindo que outras plantas tomassem os espaços não ocupados, principalmente o trevo vermelho e plantas daninhas. Segundo Pitelli (17), as plantas daninhas normalmente são favorecidas pelo pastejo seletivo e com isso apresentam maior facilidade em vencer a competição.

Para realizar o ajuste da carga animal nas diferentes ofertas de forragem a cada 14 dias, foi utilizado os valores dos resíduos de MS estimados através do Método do Disco, em razão deste método ser mais expedito. Entretanto, para teste do efeito dos tratamentos sobre as demais variáveis, optou-se pelas OF calculadas pelo Método Botanal, uma vez que além dos dados de resíduos de MS, a metodologia Botanal estima também os demais parâmetros necessários: a composição botânica e a presença de todas as espécies na pastagem.

A participação percentual dos componentes presentes na pastagem está apresentada na Tabela 2 e a relação funcional destes componentes com a OF pode ser vista na Tabela 3. apresentados pela análise de regressão entre as variáveis analisadas.

TABELA 2 - Participação na disponibilidade total de MS (\%) das espécies presentes na pastagem, submetidas a diferentes ofertas de forragem, avaliados pelo Método Botanal no período de 17/07 a 06/11/95. CEEx-Canguiri, UFPR-SCA, Pinhais-PR.

\begin{tabular}{cccccccc}
\hline $\begin{array}{c}\text { OF } \\
\text { REAL } \\
\% \mathrm{PV}\end{array}$ & PIQUETE & AZEVÉM & $\begin{array}{c}\text { TREVO } \\
\text { VERMELHO }\end{array}$ & $\begin{array}{c}\text { TREVO } \\
\text { BRANCO } \\
\% \mathrm{MS} \mathrm{ha}^{-1}\end{array}$ & $\begin{array}{c}\text { CORNI } \\
\text { CHÃO }\end{array}$ & $\begin{array}{c}\text { OUTRAS } \\
\text { POÁCEAS }\end{array}$ & $\begin{array}{c}\text { PLANTAS } \\
\text { DANINHAS }\end{array}$ \\
\hline 3,5 & 02 & 72 & 19 & 03 & 00 & 00 & 05 \\
3,8 & 05 & 84 & 11 & 01 & 01 & 01 & 03 \\
8,6 & 04 & 84 & 13 & 01 & 01 & 00 & 01 \\
9,2 & 07 & 92 & 06 & 01 & 00 & 00 & 01 \\
13,8 & 03 & 87 & 11 & 01 & 00 & 00 & 01 \\
14,0 & 06 & 91 & 08 & 01 & 00 & 00 & 00 \\
19,2 & 01 & 76 & 22 & 02 & 00 & 00 & 00 \\
19,4 & 08 & 95 & 03 & 00 & 00 & 00 & 01 \\
\hline
\end{tabular}

Verifica-se, que apenas o componente plantas daninhas apresentou significância nos modelos testados $(P<0,05)$, tanto para o modelo linear, quanto para o modelo quadrático, sendo a equação do modelo quadrático a que melhor explica o relacionamento deste componente com a OF $\left(R^{2}=0,79\right)$. O efeito da equação quadrática sobre o componente plantas daninhas deve estar relacionado aos valores obtidos no piquete 8 , que diferiu dos valores da mesma repetição obtidos no piquete 1. Por ocasião da semeadura, ocorreram falhas localizadas em reboleiras, em razão da alta cobertura do resíduo acumulado de MS da pastagem anterior (milheto + capim papuã). As falhas na germinação das forrageiras, propiciaram o aparecimento de plantas daninhas principalmente, língua-de-vaca (Rumex obtusifolus L.) e nabiça (Raphanus raphanistrum L.).

TABELA 3 - Relação linear e quadrática das variáveis analisadas no período de 17/07 a 06/11/95, com a oferta de forragem calculada, na pastagem de azevém associada com fabáceas de inverno. CEEx-Canguiri, UFPR -SCA, Pinhais-PR.

\begin{tabular}{lcccrrrrr}
\hline & & \multicolumn{3}{c}{ MODELO LINEAR } & \multicolumn{4}{c}{ MODELO QUADRÁTICO } \\
VARIÁVEIS DEPENDENTES & $\mathrm{R}^{2}$ & $\mathrm{~F}$ & $\mathrm{P}$ & $\mathrm{C} . \mathrm{V} . \%$ & $\mathrm{R}^{2}$ & $\mathrm{~F}$ & $\mathrm{P}$ & $\mathrm{C} . \mathrm{V} . \%$ \\
\hline Resíduo médio Botanal & 0,95 & 144,9 & $\mathbf{0 , 0 0 1}$ & 8,05 & 0,99 & 9631,4 & $\mathbf{0 , 0 0 1}$ & 0,71 \\
Proteína Bruta & 0,50 & 8,1 & $\mathbf{0 , 0 2 9}$ & 9,86 & 0,76 & 11,9 & $\mathbf{0 , 0 1 2}$ & 6,89 \\
Fibra Detergente Ácido & 0,59 & 11,0 & $\mathbf{0 , 0 1 6}$ & 4,00 & 0,86 & 21,8 & $\mathbf{0 , 0 0 3}$ & 2,37 \\
Fibra Detergente Neutro & 0,58 & 10,7 & $\mathbf{0 , 0 1 7}$ & 2,43 & 0,84 & 19,7 & $\mathbf{0 , 0 0 4}$ & 1,49 \\
Relação Folha/Colmo & 0,58 & 10,8 & $\mathbf{0 , 0 1 7}$ & 18,37 & 0,65 & 7,5 & $\mathbf{0 , 0 3 1}$ & 16,75 \\
Oferta Forragem Disco & 0,99 & 1457,4 & $\mathbf{0 , 0 0 1}$ & 3,38 & 0,99 & 1149,3 & $\mathbf{0 , 0 0 1}$ & 2,69 \\
Resíduo médio Disco & 0,98 & 296,0 & $\mathbf{0 , 0 0 1}$ & 3,83 & 0,98 & 203,1 & $\mathbf{0 , 0 0 1}$ & 3,29 \\
Azevém (\%) & $-0,01$ & 0,9 & 0,366 & 9,35 & 0,09 & 1,3 & 0,341 & 8,90 \\
Trevo Vermelho (\%) & $-0,14$ & 0,2 & 0,707 & 58,42 & $-0,19$ & 0,4 & 0,663 & 59,70 \\
Trevo Branco (\%) & 0,04 & 1,3 & 0,304 & 69,60 & $-0,02$ & 0,9 & 0,455 & 71,68 \\
Cornichão (\%) & 0,15 & 2,2 & 0,186 & 170,80 & $-0,02$ & 0,9 & 0,454 & 187,20 \\
Plantas Daninhas (\%) & 0,54 & 9,3 & $\mathbf{0 , 0 2 2}$ & 76,13 & 0,79 & 14,4 & $\mathbf{0 , 0 0 8}$ & 51,33 \\
Total Leguminosas (\%) & $-0,11$ & 0,3 & 0,590 & 57,39 & $-0,15$ & 0,5 & 0,615 & 58,57 \\
\hline
\end{tabular}

OBS.: Os dados em negrito apresentaram significância estatística, ao nível de $5 \%$ de probabilidade. $\mathrm{R}^{2}=$ Coeficiente de Determinação Ajustado; $\mathrm{F}=$ teste $\mathrm{F} ; \mathrm{P}=$ Probabilidade;C.V. = Coeficiente de Variação. 
Portanto, considerar, à medida em que ocorre diminuição na oferta de forragem, seja pelo acréscimo de animais ou pela redução do resíduo de MS na pastagem o aumento gradativo na quantidade de plantas daninhas, conforme Figura 1. Isto ocorreu, porque o azevém além de diminuir significativamente a sua participação na composição botânica da pastagem (Tabela 4), apresentou menor vigor de rebrote, devido ao pastejo intenso e freqüente, reduzindo a quantidade de gemas potencialmente ativas e a área fotossintética das plantas. Assim, conforme afirma Maraschin (10), o superpastejo de plantas eretas ou cespitosas sem que se permita certo descanso e onde os novos afilhos estejam sendo continuamente pastejados, reduz os níveis de reservas orgânicas das plantas, comprometendo a sua persistência. Confirmado também por Silva (20), em experimento com capim-elefante anão (Pennisetum purpureum Schum. cv. Mott) em sistema de pastejo rotacionado, nos piquetes em que se ofertou de 6 a $3 \mathrm{~kg}$ de MS $100 \mathrm{~kg}^{-1}$ de PV a vegetação apresentou menor porte, alta relação folha: colmo e intensa invasão por capim braquiária (Brachiaria decumbens Stapf.). Da mesma forma, Mott (15) afirma que em pastejo contínuo com baixa OF pode-se eliminar as poáceas e as fabáceas desejáveis, resultando na dominância de plantas daninhas.

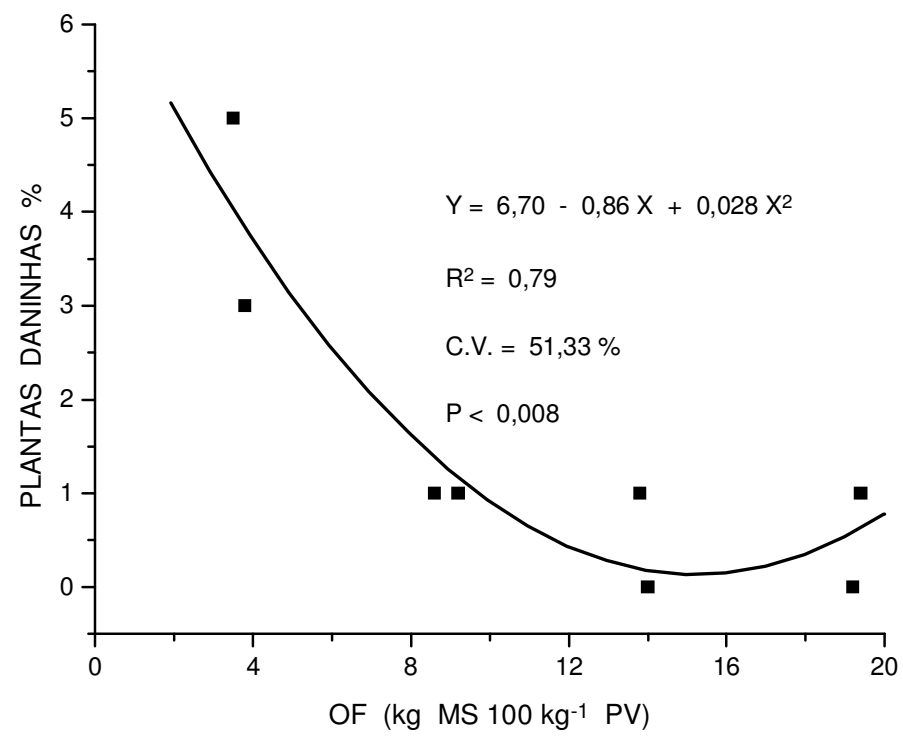

FIGURA 1 - Relação entre a percentagem de plantas daninhas com a oferta de forragem (OF) utilizada na pastagem de azevém, associada com fabáceas de inverno, avaliada no período de 17/07 a 06/11/95, no CEEx-Canguiri, UFPR-SCA, Pinhais-

Mesmo não havendo efeito da OF sobre os outros componentes da composição botânica da pastagem, convém salientar a ótima participação do azevém nos piquetes (Tabela 4), tornando-se dominante em todo o período de avaliação (variação de 77 a $99 \%$ ), enquanto que as fabáceas aumentaram a participação em outubro e novembro, principalmente, o trevo vermelho (participação de 6 a 39\%). Isto ocorreu em função da menor competição exercida pelo azevém por estar em final de ciclo (fase reprodutiva). A participação das fabáceas perenes, trevo branco e cornichão foi insignificante, pois são espécies de lento estabelecimento e sofrem maior competição pelo sombreamento exercido nesta associação.

Contudo, a contribuição destas espécies pode ser relevante a partir do segundo ano pois sua presença na área eram de freqüência inicial elevada (Tabela 5). 
IDO, O.T. et al. Composição botânica e qualidade de...

TABELA 4 - Percentagem do componente azevém na pastagem, nos piquetes (PIQ) experimentais ao longo do período de avaliação. CEEx-Canguiri, UFPR-SCA, Pinhais-PR, 1995.

\begin{tabular}{ccccccccc}
\hline DATA AMOSTRAGEM & PIQ 1 & PIQ 2 & PIQ 3 & PIQ 4 & PIQ 5 & PIQ 6 & PIQ 7 & PIQ 8 \\
\hline 15/07/95 & 94 & 81 & 97 & 94 & 94 & 98 & 94 & 98 \\
11/08/95 & 83 & 77 & 90 & 92 & 88 & 93 & 94 & 95 \\
05/09/95 & 88 & 83 & 97 & 95 & 92 & 96 & 98 & 99 \\
$09 / 10 / 95$ & 62 & 58 & 80 & 82 & 72 & 83 & 89 & 94 \\
$06 / 11 / 95$ & 57 & 60 & 69 & 58 & 74 & 84 & 86 & 89 \\
\hline
\end{tabular}

TABELA 5 - Percentagem de freqüência média das espécies presentes na pastagem, nos piquetes experimentais, nos períodos de avaliação. CEEx-Canguirí, SCA, UFPR, Pinhais-PR, 1995.

\begin{tabular}{ccccccc}
\hline PIQUETE & AZEVÉM & $\begin{array}{c}\text { TREVO } \\
\text { VERMELHO }\end{array}$ & $\begin{array}{c}\text { TREVO } \\
\text { BRANCO }\end{array}$ & $\begin{array}{c}\text { CORNI- } \\
\text { CHÃO }\end{array}$ & $\begin{array}{c}\text { OUTRAS } \\
\text { GRAMÍNEAS }\end{array}$ & $\begin{array}{c}\text { PLANTAS } \\
\text { DANINHAS }\end{array}$ \\
\hline 01 & 99 & 88 & 61 & 58 & 08 & 15 \\
02 & 100 & 85 & 46 & 55 & 10 & 09 \\
04 & 100 & 74 & 26 & 31 & 07 & 07 \\
05 & 100 & 83 & 43 & 54 & 02 & 07 \\
06 & 100 & 81 & 35 & 41 & 01 & 03 \\
07 & 100 & 91 & 63 & 58 & 00 & 06 \\
08 & 100 & 70 & 07 & 08 & 03 & 03 \\
\hline
\end{tabular}

A qualidade da pastagem avaliada em percentagem de proteína bruta (PB), fibra em detergente neutro (FDN), fibra em detergente ácido (FDA) e relação folha:colmo (F:C) presente na MS da pastagem pode ser vista na Tabela 6 .

Conforme visto na Tabela 3 houve significância $(P<0,05)$ para a relação entre a percentagem de PB e a OF, tanto para o modelo linear como para o modelo quadrático. Observa-se que a regressão quadrática $(P<0,013)$ apresentou o melhor ajuste para esta relação. Verifica-se na Figura 2, à medida em que reduziu-se a OF houve aumento na percentagem de PB da forragem, provavelmente porque houve persistência das fábaceas dentro da composição botânica da pastagem, principalmente do trevo vermelho.

TABELA 6 - Proteína Bruta, fibra em Detergente Ácido, fibra em Detergente Neutro e relação folha:colmo na pastagem de azevém associada com fabáceas de inverno, submetida a diferentes ofertas de forragem, no período de 17/07 a 06/11/95. CEExCanguiri, SCA - UFPR, Pinhais-PR.

\begin{tabular}{|c|c|c|c|c|c|}
\hline $\begin{array}{c}\text { OFERTA } \\
\text { FORRAGEM } \\
\text { REAL } \\
\% \mathrm{PV}\end{array}$ & $\begin{array}{c}\text { PIQUETE } \\
\mathrm{N}^{\circ}\end{array}$ & PB & $\begin{array}{c}\text { FDA } \\
\%\end{array}$ & FDN & $\begin{array}{c}\text { RELAÇÃO } \\
F: C\end{array}$ \\
\hline 3,5 & 02 & 21,3 & 27,1 & 51,2 & 1,40 \\
\hline 3,8 & 05 & 20,3 & 28,4 & 52,6 & 1,48 \\
\hline 8,6 & 04 & 16,0 & 31,1 & 55,2 & 0,82 \\
\hline 9,2 & 07 & 15,6 & 31,3 & 55,0 & 1,30 \\
\hline 13,8 & 03 & 15,9 & 31,9 & 56,6 & 0,92 \\
\hline 14,0 & 06 & 16,4 & 31,9 & 56,6 & 0,76 \\
\hline 19,2 & 01 & 16,8 & 30,9 & 54,9 & 0,88 \\
\hline 19,4 & 08 & 14,5 & 32,7 & 57,1 & 0,80 \\
\hline
\end{tabular}




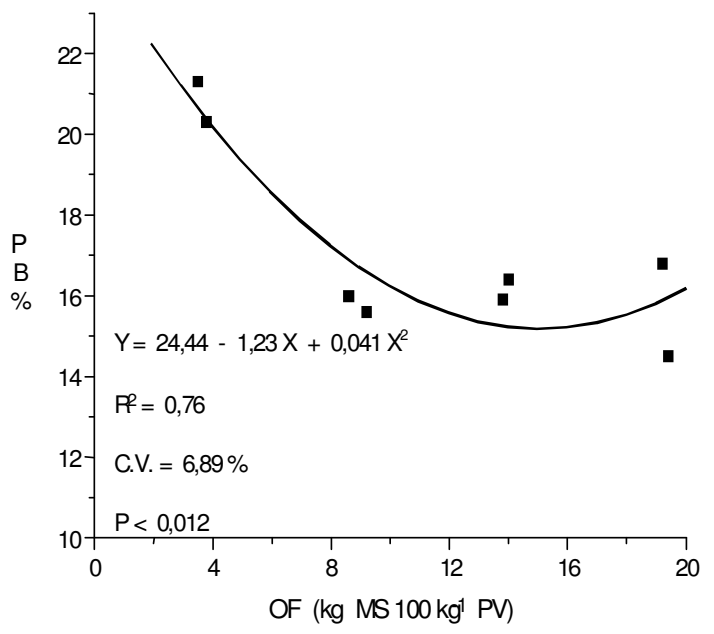

FIGURA 2 - Relação entre a percentagem média de proteína bruta com a oferta de forragem utilizada na pastagem de azevém, associada com fabáceas de inverno, avaliada no período de 17/07 a 06/11/95. CEEx - Canguiri, SCA - UFPR, Pinhais-PR.

Verifica-se na Tabela 7 , decréscimo gradativo na PB (\%) do início (julho) para o meio (setembro) do período experimental, com o avanço na estação de crescimento, o que seria esperado em função do desfolhamento causado pelo pastejo, da redução na taxa de acúmulo de MS devido à baixa precipitação ocorrida entre os meses de agosto a setembro e também da diminuição na relação folha:colmo do azevém (Tabela 8 ). Entretanto, o aumento da participação relativa do trevo vermelho (Tabela 9), em um estádio em que a planta apresenta altos valores de PB contribui para elevação dos teores de PB no último período de avaliação. Nos meses de outubro/novembro o azevém passa para o estádio reprodutivo (floração e enchimento de grão), com redução no teor protéico da forragem como conseqüência natural da maturidade da planta $(8 ; 13)$. Portanto, o efeito da equação quadrática sobre a PB (\%) está relacionado principalmente com a participação do trevo vermelho, cujos dados apresentados principalmente no piquete 01 diferem dos dados da mesma repetição verificada no piquete 08 , devido as dificuldades de implantação (equipamentos, e distribuição de sementes) o que ocasionou diferenças na PB (\%), pela diferentes contribuições das fabáceas (Tabela 9).

TABELA 7 - Percentagem de proteína bruta, das amostras de matéria seca total da pastagem de azevém associada com fabáceas de inverno, nos piquetes experimentais ao longo do período de avaliação. CEEx - Canguiri, SCA -UFPR, Pinhais-PR, 1995.

\begin{tabular}{ccccccccc}
\hline DATA AMOSTRA-GEM & PIQ 1 & PIQ 2 & PIQ 3 & PIQ 4 & PIQ 5 & PIQ 6 & PIQ 7 & PIQ 8 \\
\hline $11 / 07 / 95$ & 25,7 & 28,1 & 25,8 & 22,8 & 26,4 & 24,2 & 23,2 & 24,9 \\
$11 / 08 / 95$ & 15,5 & 18,0 & 14,1 & 14,2 & 16,8 & 15,2 & 14,0 & 14,7 \\
$11 / 09 / 95$ & 11,3 & 15,1 & 10,7 & 10,8 & 14,1 & 10,9 & 10,5 & 9,7 \\
$06 / 10 / 9$ & 13,2 & 21,0 & 12,7 & 14,2 & 19,7 & 13,4 & 13,6 & 9,3 \\
$06 / 11 / 95$ & 18,3 & 24,3 & 16,3 & 17,9 & 24,5 & 18,4 & 16,9 & 14,1 \\
\hline
\end{tabular}

TABELA 8 - Relação Folha:Colmo das amostras da pastagem de azevém, associada com fabáceas de inverno nos piquetes ao longo do período de avaliação. CEEx-Canguiri, SCA - UFPR, Pinhais-PR, 1995.

\begin{tabular}{ccccccccc}
\hline DATA & & & & & & & & \\
AMOSTRAGEM & PIQ 1 & PIQ 2 & PIQ 3 & PIQ 4 & PIQ 5 & PIQ 6 & PIQ 7 & PIQ 8 \\
\hline $14 / 07 / 95$ & 2,7 & 4,0 & 3,0 & 2,2 & 4,5 & 2,2 & 4,5 & 2,1 \\
11/08/95 & 0,9 & 0,8 & 0,7 & 0,8 & 0,8 & 0,7 & 0,9 & 1,1 \\
08/09/95 & 0,3 & 0,4 & 0,3 & 0,4 & 0,4 & 0,4 & 0,5 & 0,3 \\
06/10/95 & 0,3 & 0,7 & 0,3 & 0,4 & 0,6 & 0,3 & 0,3 & 0,3 \\
03/11/95 & 0,2 & 1,1 & 0,3 & 0,3 & 1,1 & 0,2 & 0,3 & 0,2 \\
\hline
\end{tabular}


IDO, O.T. et al. Composição botânica e qualidade de...

TABELA 9 - Percentagem do componente trevo vermelho presente na pastagem, nos piquetes ao longo do período de avaliação. CEEx-Canguiri, SCA - UFPR, Pinhais-PR, 1995.

\begin{tabular}{ccccccccc}
\hline $\begin{array}{c}\text { DATA } \\
\text { AMOSTRAGEM }\end{array}$ & PIQ 1 & PIQ 2 & PIQ 3 & PIQ 4 & PIQ 5 & PIQ 6 & PIQ 7 & PIQ 8 \\
\hline 15/07/95 & 15 & 17 & 2 & 4 & 6 & 2 & 5 & 1 \\
$11 / 08 / 95$ & 8 & 9 & 3 & 4 & 8 & 2 & 3 & 1 \\
$05 / 09 / 95$ & 12 & 13 & 3 & 5 & 7 & 4 & 1 & 0 \\
$09 / 10 / 95$ & 36 & 26 & 19 & 15 & 18 & 16 & 9 & 6 \\
$06 / 11 / 95$ & 39 & 31 & 26 & 39 & 17 & 15 & 13 & 7 \\
\hline
\end{tabular}

$\mathrm{Na}$ Tabela 6 podem ser vistos os dados referente à relação folha : colmo. O relacionamento desta variável com a OF está apresentado na Tabela 3 , indicando significância para os modelos linear e quadrático $(P<0,05)$. O melhor ajuste obtido foi representado pela regressão linear entre as variáveis $(P<0,017)$. A equação gerada por este modelo com a variável relação $\mathrm{F}: \mathrm{C}$ está apresentada na Figura 3.

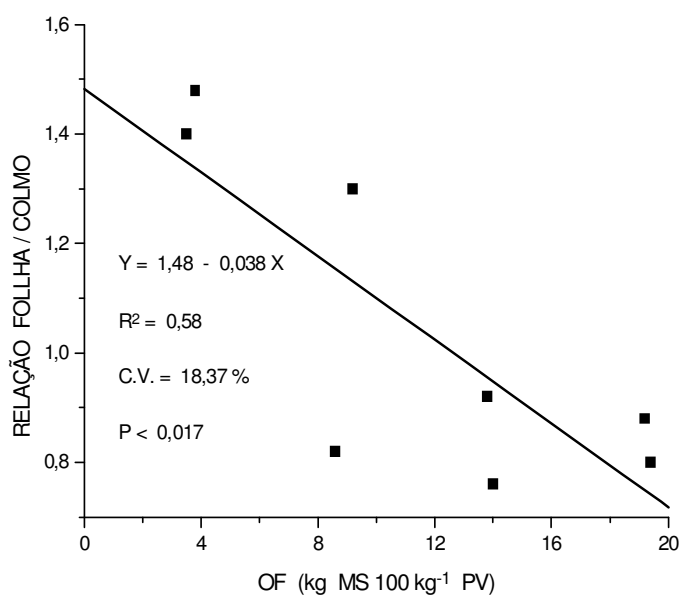

FIGURA 3 - Relação folha : colmo com a oferta de forragem utilizada na pastagem de azevém, associada com fabáceas de inverno, avaliada no período de 17/07 a 06/11/95. CEEx - Canguiri, SCA - UFPR, Pinhais-PR.

Observa-se que os maiores valores registrados para a relação $\mathrm{F}: \mathrm{C}$ estão associados à menor OF, indicando que a sua diminuição provocou mudança na estrutura da pastagem através da maior relação $\mathrm{F}: \mathrm{C}$. Fato também verificado em pastagem de milheto por Moraes (13). Nas maiores OF resultaram resíduos

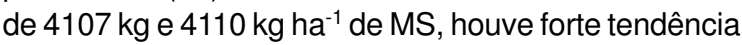
para a redução na relação $F: C$, enquanto que nas menores OF onde os resíduos foram de $1322 \mathrm{~kg}$ e $1436 \mathrm{~kg} \mathrm{ha}^{-1}$ ocorreu aumento na relação $\mathrm{F}: C$, situação esta que é mais favorável à qualidade da forragem, uma vez que o conteúdo de PB é mais alto na fração das folhas do que nos colmos (21). A relação $F: C$ foi $71 \%$ maior na menor OF em relação a maior OF, o que contribuiu para explicar a maior $\%$ de $\mathrm{PB}$ encontrada na forragem dos tratamentos de menor OF. Resultados semelhantes foram obtidos por Veiga et al. (24) e por Silva (20) com capim-elefante anão, onde os maiores valores de PB e a alta relação folha:colmo foram observados na vegetação dos piquetes submetidos à menor oferta de forragem.

Conforme visto na Tabela 3 , houve significância $(P<0,05)$ para a relação entre a percentagem de FDN e de FDA com a OF tanto para o modelo linear quanto para o modelo quadrático. Observa-se tanto para a FDN como para a FDA, que a regressão quadrática apresenta melhor ajuste para as relações com a OF (Figuras 4 e 5). A medida em que reduzia-se a OF ocorria redução na FDN (\%). Com o aumento da OF, ocorreu aumento na FDN (\%), até a OF intermediária, seguida da diminuição na FDN (\%) com novo aumento da OF. O teor de FDN de uma forragem aumenta com seu desenvolvimento e é maior no colmo que nas folhas e maior nas poáceas que nas fabáceas (23). Situação idêntica ocorreu com a fração FDA (Figura 5). 


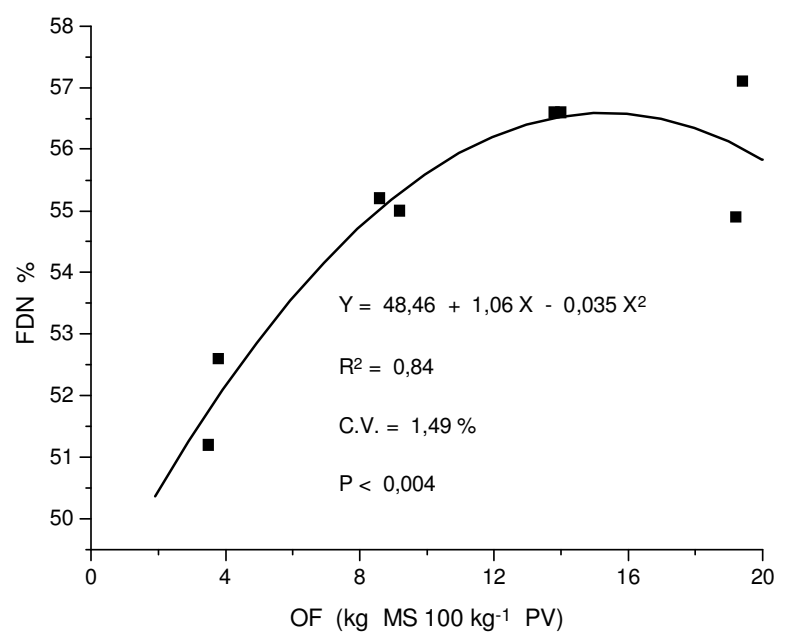

FIGURA 4 - Relação entre a percentagem média de fibra em detergente neutro (\%) com a oferta de forragem utilizada na pastagem de azevém, associadacom fabáceas de inverno, avaliada no período de 17/07 a 06/11/95. CEEx-Canguiri, SCA UFPR, Pinhais-PR

A medida em que reduzia-se a OF ocorria redução na FDN (\%). Com o aumento da OF, ocorreu aumento na FDN (\%), até a OF intermediária, seguida da diminuição na FDN (\%) com novo aumento da OF.
O teor de FDN de uma forragem aumenta com seu desenvolvimento e é maior no colmo que nas folhas e maior nas poáceas que nas fabáceas (23). Situação idêntica ocorreu com a fração FDA (Figura 5).

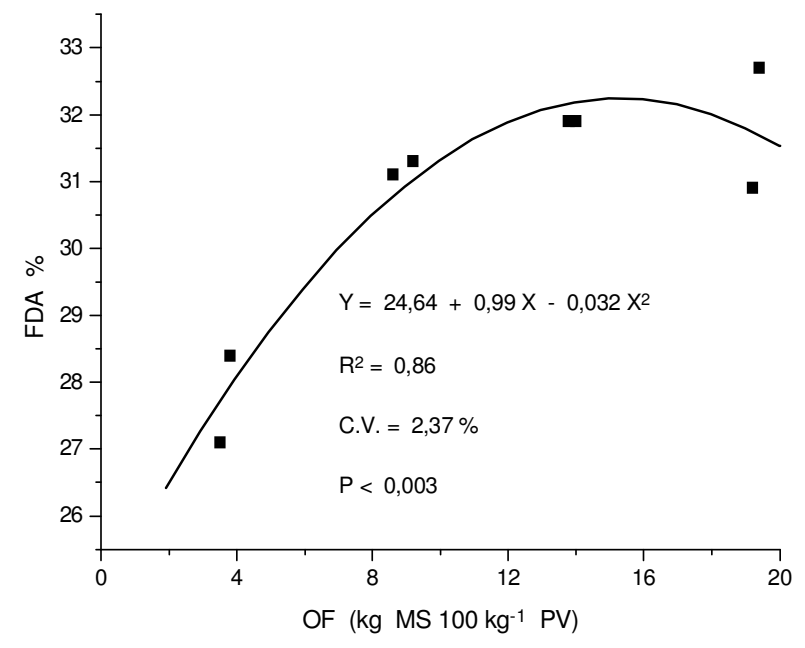

FIGURA 5 - Relação entre a percentagem média de fibra em detergente ácido com a oferta de forragem utilizada na pastagem de azevém, associada com fabáceas de inverno, avaliada no período de 17/07 a 06/11/95. CEEx -Canguiri, SCA - UFPR, 


\section{CONCLUSÕES}

Ocorre aumento na taxa de desaparecimento de massa seca da pastagem e aumento na relação folha:colmo com a diminuição da oferta de forragem, indicando melhor aproveitamento do alimento pelos animais;

Com o avanço no estádio de desenvolvimento do azevém, há decréscimo gradativo no teor de proteína bruta na associação, no entanto com aumento da participação das fabáceas, principalmente o trevo vermelho, há aumento gradativo no teor protéico;

Para maiores ofertas de forragem há necessidade de reduzir a carga animal por unidade de área, resultando na melhor cobertura da área e num melhor equilíbrio na composição botânica da pastagem;

Há associação favorável entre a maior oferta de forragem com cobertura da área e conseqüente diminuição na percentagem de plantas daninhas.

\section{REFERÊNCIAS BIBLIOGRÁFICAS}

1. ALCÂNTARA, P.B.; ABRAMIDES, P.L.G.; ROCHA, G.L. da. Efeito da quantidade de leguminosas presentes em pastagens de gramíneas tropicais, sobre o ganho de peso de bovinos de corte. Zootecnia, Nova Odessa, v.17, n.4, p. 225-38, 1979.

2. BARRETO, I.L. Pastejo contínuo. In: PASTAGENS: Fundamentos da exploração racional. -2. ed., Piracicaba: FEALQ, 1994. p. 429-453, (Série atualização em Zootecnia, v.10).

3. BRYAN, W.W. Tropical and subtropical frests and heaths. In: MOORE, R.M., (Ed.) Australian grasslands. Canberra: Australian National University Press, 1970. p. 101-111.

4. BRYAN, W.W.; EVANS, T.R. Legume-based pastures. Annual Report. Australia: CSIRO- Division of Tropical Pastures, Melbourne, 1968. p.21-22.

5. ESCOSTEGUY, C.M.D. Avaliação agronômica de uma pastagem natural sob níveis de pressão de pastejo. Porto Alegre, 1990. 231f. Dissertação (Mestrado em Zootecnia) -Faculdade de Agronomia, Universidade Federal do Rio Grande do Sul. 1990.

6. INSTITUTO AGRONÔMICO DO PARANÁ. Cartas Climáticas do Estado do Paraná 1994. Londrina, PR., 1994. $49 \mathrm{p}$. (IAPAR. Documento, 18).

7. JONES, R.M.; HARGREAVES, J.N.G. Improvements to the dry-weight-rank method for measuring botanical composition. Grass and Forage Science, Oxford, v.34, p.181-9, 1979.

8. KEPLIN, L.A. da S. Forrageiras e o plantio direto. In: SIMPÓSIO INTERNACIONAL SOBRE PLANTIO DIRETO EM SISTEMAS SUSTENTÁVEIS. (1993: Castro-PR). Anais. Castro: Fundação ABC, 1993. p.238-252.

9. KOEHLER, H.S. Manual de uso do programa MSTAT. Curitiba: UFPR /SCA-Departamento de Fitotecnia e Fitossanitarismo, 1996. 38p.

10. MARASCHIN, G.E. Sistemas de pastejo. 1. In: PASTAGENS: Fundamentos da exploração racional -2. ed., Piracicaba: FEALQ, 1994 p.401-428, (Série atualização em Zootecnia, v.10).

11. MOOJEN, E.L. Dinâmica e PIQencial produtivo de uma pastagem nativa do Rio Grande do Sul, submetida a pressões de pastejo, épocas de diferimento e níveis de adubação. Porto Alegre, 1991. 172p. Tese (Doutorado em Zootecnia)- Faculdade de Agronomia, Universidade Federal do Rio Grande do Sul. 1991.

12. MOORE, J.E.; MOTT, G.O. Structural inhibitors of quality in tropical grasses. In: ANTI-QUALITY COMPONENTS OF FORAGES. Madison: Crop Science Society of America, 1973. p.53-98.

13. MORAES, A. de. Pressões de pastejo e produção animal em milheto (Pennisetum americanum (L.) Leeke). Porto Alegre, 1984. 104f. Dissertação (Mestrado em Fitotecnia)- Faculdade de Agronomia, Universidade Federal do Rio Grande do Sul. 1984.

14. MORAES, A. de.; MARASCHIN, G.E.; NABINGER, C. Pastagens nos ecossistemas de clima subtropical: Pesquisas para o desenvolvimento sustentável. In: SIMPÓSIO SOBRE PASTAGENS NOS ECOSSISTEMAS BRASILEIROS: PESQUISAS PARA O DESENVOLVIMENTO SUSTENTÁVEL. (1995: Brasília). Anais. Brasília: Sociedade Brasileira de Zootecnia, 1995. p.146200.

15. MOTT, G.O. Relationship of available forage and animal performance in tropical grazing systems. In: 1984 FORAGE AND GRASSLAND CONFERENCE, (1984: Houston, Texas). Proceedings. Lexington: American Forage and Grassland Council. 1984. p.373-7.

16. MOTT, G.O.; LUCAS, H.L. The design, conduct and interpretation of grazing trials on cultivated and improved pastures. In: INTERNATIONAL GRASSLAND CONGRESS, (6.: 1952: Pensylvania). Proceedings. Pensylvania: State College Press, 1952. p.1380-1385.

17. PITELLI, R.S. Ecologia de plantas invasoras em pastagens. In: SIMPÓSIO SOBRE ECOSSISTEMA DE PASTAGENS, (1989: Jaboticabal). Anais. Jaboticabal: FUNEP, 1989. p.69-86.

18. QUADROS, F.L.P.; MARASCHIN,G.E. Desempenho animal em misturas de espécies forrageiras de estaçao fria. Pesquisa Agropecuária Brasileira, Brasília, v.22 n.5, p.535-541, 1987.

19. ROBERTS, C.R. Algunas causas comunes del fracasso de praderas de leguminosas y gramineas tropicais en fincas comerciales y posibiles solúciones. In: TERGAS, L.E.; SANCHES, P.A. (Ed.) Produccion de Pastos en Suelos Ácidos de los Tropicos. Cali, Colombia: Editora, 1979. p.427-445.

20. SILVA, D.S. Efeito da pressão de pastejo sobre a estrutura, a produtividade e persistência do capim-elefante anão (Pennisetum purpureum Schum. cv. Mott). Viçosa, 1993. 88p. Tese (Doutorado em Zootecnia), Universidade Federal de Viçosa. 1993.

21. STOBBS, T.H. The effect of plant structure on the intake of tropical pastures. I. Variation in bite size of grazing cattle. Australian Journal of Agricultural Research. Victoria, v.24, p.809-819, 1973. 
IDO, O.T. et al. Composição botânica e qualidade de...

22. TOTHILL, J.C.; HARGREAVES, J.N.G.; JONES,R.M. Botanal - a comprehensive sampling and computing method for estimating pasture yield and composition. I. Field sampling. Brisbane, CSIRO, Division of Tropical Crops and Pastures. 1978. 20p. (Tropical Agronomy Technical Memorandum, n.8).

23. VAN SOEST, P.J. Nutritional ecology of the ruminant. Corvalis: Cornell University, 1983. p.88.

24. VEIGA, J.B.; MOTT, G.O.; RODRIGUES, L.R.A. et al. Capim-elefante anão sob pastejo. I. Produção de forragem. II. Valor nutritivo. Pesquisa Agropecuária Brasileira, Brasília, v.20, n.8, p.929-944, 1985.

Recebido em 15/08/2003 Aceito em 30/11/2005 